\title{
Scrub typhus masquerading as an acute lower respiratory tract infection
}

\author{
Manouri P Senanayake $^{1}$, Arundathi Jayasena ${ }^{2}$ \\ Sri Lanka Journal of Child Health, 2012; 41(2): 97-98
}

(Key words: Scrub typhus; respiratory tract infection)

\section{Introduction}

Pneumonitis is the commonest chest manifestation of scrub typhus and indicates severe disease ${ }^{1,2}$. However, in the differential diagnosis of a child with acute respiratory infection, scrub typhus is seldom considered. Scrub typhus pneumonitis is usually diagnosed in the late stages of the disease when other features such as characteristic rash, lymphadenopathy and hepatomegaly are also present. The pathognomonic eschar is not seen in all patients ${ }^{3}$. We report a febrile child with interstitial pneumonia with no other clinical features of typhus apart from an eschar. Diagnosis was serologically confirmed and complete recovery followed intravenous chloramphenicol.

\section{Case report}

A 3 year old boy from a farming village in the North Central Province of Sri Lanka presented in the second week of a febrile illness associated with chills, myalgia, irritability and a troublesome cough. Systems examination only found tachypnoea (respiratory rate $40 / \mathrm{min}$ ), intercostal, and subcostal recessions, scattered rhonchi and a percutaneous oxygen saturation of $92 \%$ but an eschar was found buried in a skin fold in the neck (Figure 1). There was no significant hepatomegaly. Chest $\mathrm{X}$ ray (Figure 2) showed interstitial pneumonitis. Weil Felix agglutination reaction was positive for OXK strain (titre 1/320). Oxygen therapy, bronchodilators and amoxicillin caused no improvement but defervescence occurred within 36 hours of commencing intravenous chloramphenicol.

\section{Discussion}

Scrub typhus caused by Orientia tsutsugamushi, is a re-emerging rickettsial infection in Sri Lanka ${ }^{4}$. The

\footnotetext{
${ }^{1}$ Professor in Paediatrics, Department of Paediatrics, Faculty of Medicine, Colombo, ${ }^{2}$ Registrar in Paediatrics, Lady Ridgeway Hospital, Colombo
}

(Received on 20 July 2011: Accepted after revision on 9 September 2011)

clinical picture can be varied and has been reported to mimic typhoid ${ }^{5}$. We report a patient in whom the predominant clinical presentation was prolonged fever and severe chest infection with no other characteristic features of scrub typhus other than an eschar. This case report highlights the need for a high degree of suspicion in acutely ill, febrile children from endemic areas because the clinical picture of scrub typhus can be atypical. An eschar is not invariably present in scrub typhus and in our patient the diagnosis would have been missed had it not been for this which was the only suggestive sign.

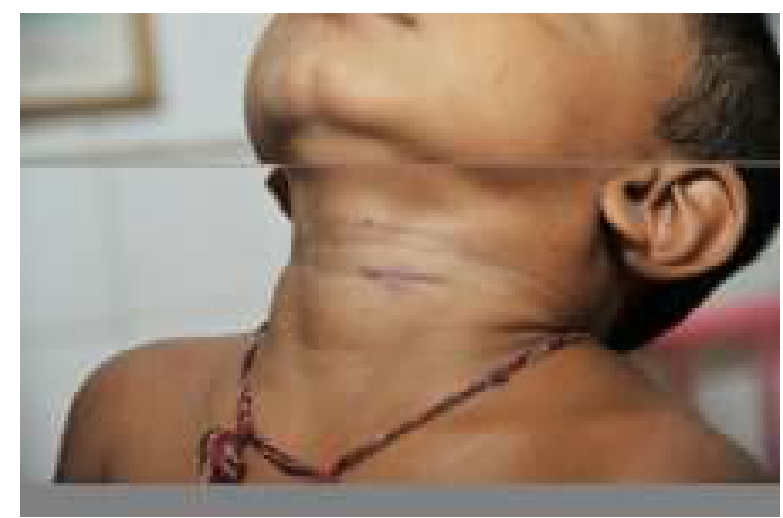

Figure 1: Eschar buried in the skin folds of the neck

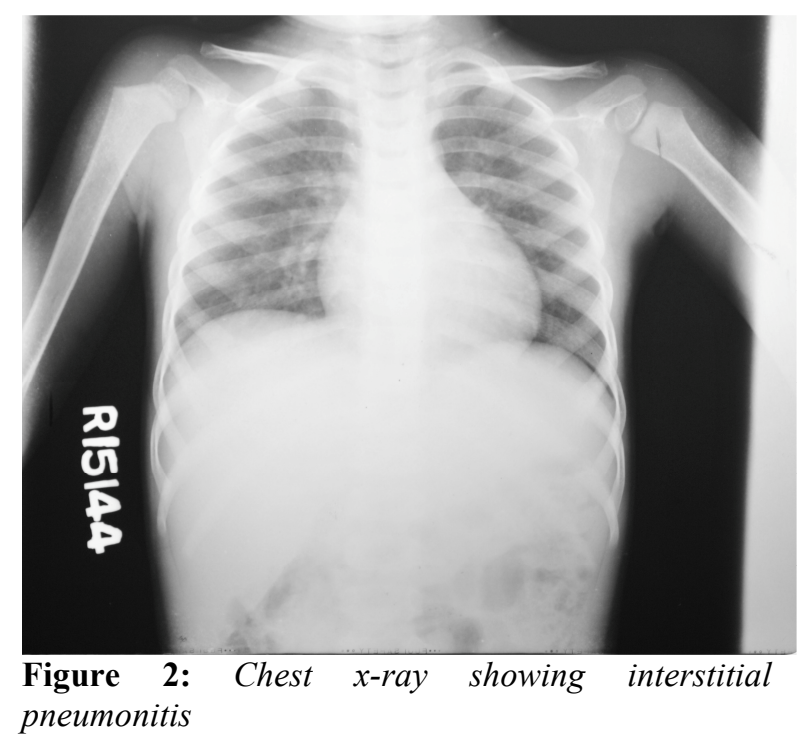




\section{References}

1. Song SW, Kim KT, Ku YM. Clinical role of interstitial pneumonia in patients with scrub typhus: a possible marker of disease severity. Journal of Korean Medical Science 2004; 19: 668-73.

http://dx.doi.org/10.3346/jkms.2004.19.5.668

2. Chayakul P, Panich V, Silpapojakul K. Scrub typhus pneumonitis: an entity which is frequently missed. Quarterly Journal of Medicine 1988; 68: 595-602.

3. Kliegman RM, Behrman RE, Jenson HB, Stanton BF. Scrub typhus. Nelson's Textbook of Paediatrics, $18^{\text {th }}$ ed. vol-1. 1295-6.
4. Premaratna R, Loftis AD, Chandrasena TG, Dasch GA, de Silva HJ. Rickettsial infections and their clinical presentations in the Western Province of Sri Lanka: a hospital-based study. International Journal of Infectious Disease. 2008; 12(2):198-202.

http://dx.doi.org/10.1016/j.ijid.2007.06.009

5. Premaratna R, Nawasiwatte BMTP, Niriella MA, Chandrasena TGAN, Bandara NKBKRGW, Rajapakse RPVJ, de Silva HJ. Scrub typhus mimicking enteric fever; A report of three patients. Transactions of the Royal Society of Tropical Medicine \& Hygiene 2010; 104(4): 309-10.

http://dx.doi.org/10.1016/j.trstmh.2009.08.011 